\title{
ENDOTHERAPY FOR OESOPHAGEAL ANASTOMOTIC LEAKS - IS IT THE WAY FORWARD?
}

\author{
Siriwardena R C ${ }^{1}$, Pathirana A A ${ }^{2}$, Nanayakkara K ${ }^{3}$ \\ ${ }^{1}$ Senior Registrar, Department of Gastroenterological Surgery, Teaching Hospital, Colombo \\ South, ${ }^{2}$ Senior Lecturer, Department of Surgery, University of Sri Jayewardenepura, ${ }^{3}$ Consultant \\ Gastroenterological Surgeon, Teaching Hospital, Colombo South.
}

\section{R C Siriwardena}

Senior Registrar, Department of Gastroenterological Surgery, Teaching Hospital Colombo South.

\section{AAPathirana \\ Senior Lecturer, Department of Surgery, University of Sri Jayewardenepura. \\ K Nanayakkara \\ Consultant Gastroenterological Surgeon, Teaching Hospital Colombo South. \\ Corresponding author: \\ A Pathirana, 270/9 Thimbirigasyaya Road, Colombo 5. \\ Tel: 0777393003 \\ E-mail: aloka@slt.lk}

\section{Introduction}

Leaks after thoracic oesophageal anastomosis are reported in 5-7 \% of the cases (1). Traditionally these leaks are reported to carry a high mortality rate, of about $30 \%$ (2). The principles of managing this challenging complication include control of leak, drainage of collection and control of sepsis. Salvage surgery is being largely replaced by non invasive techniques. We report the management of two patients who developed leaks after thoracic oesophageal anastomosis.

\section{Case 1}

A 64-year old female underwent two stage Lewis Tanner oesophagectomy for lower oesophageal cancer at $35 \mathrm{~cm}$. Gastrografin study done on day 6 showed no evidence of an anastomotic leak. Patient was started on oral feeds. Her condition gradually deteriorated thereafter. She developed a significant right sided pleural effusion. Thorax was re-opened to drain the effusion. Endoscopy done on day 15 showed a $50 \%$ dehiscence of the anastomosis. A self expandable NITINOL $12 \mathrm{~cm}$ covered stent (Ultraflex ${ }^{\mathrm{TM}}$ Esophageal NG Stent System. Boston Scientific) was deployed. Patient made a rapid recovery. Oral feeding was started after 24 hours. She was symptom free 13 months after the surgery.

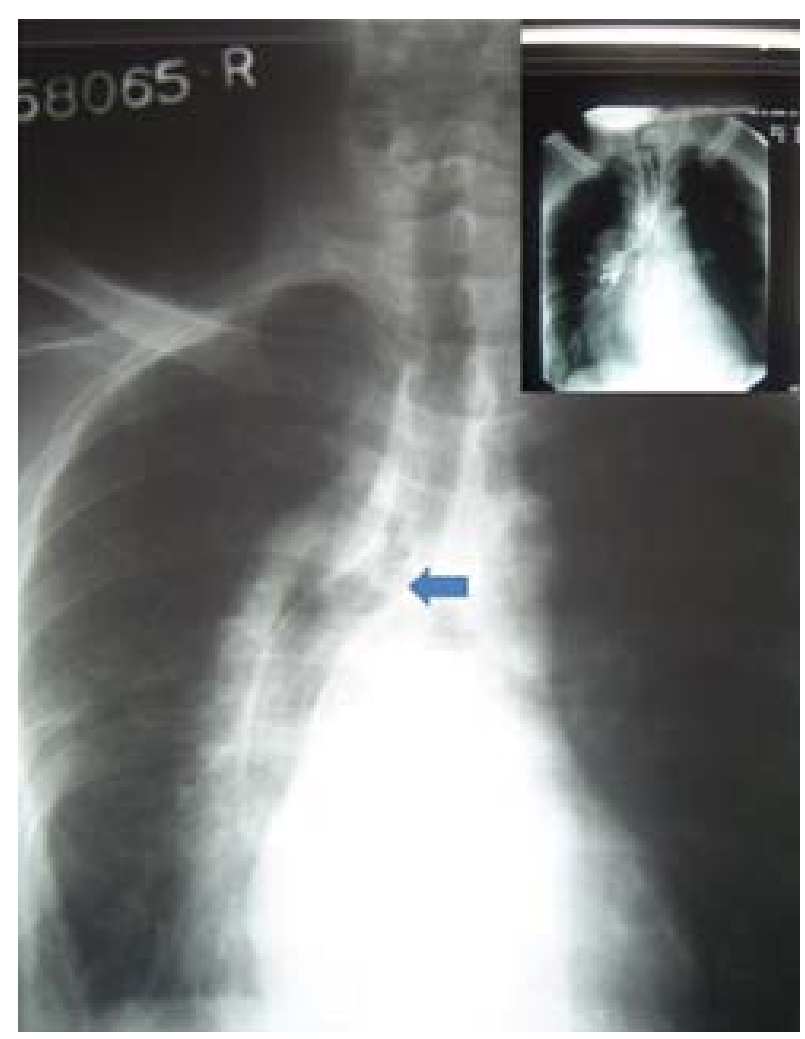

Figure 1. Gastrografin study showing nastomotic dehiscence and subsequent placement of the stent shown with an arrow. 


\section{Case 2}

A 57-year old male underwent subtotal oesophagectomy with thoracic anastomosis for a corrosive stricture. Gastrografin study done on day 7 demonstrated an anastomotic dehiscence. Second line broad-spectrum antibiotics were started immediately after diagnosis of the leak. Endoscopy revealed a 25\% anastomotic dehiscence. Within 4 hours, a self expandable NITINOL $12 \mathrm{~cm}$ covered stent (Ultraflex ${ }^{\mathrm{TM}}$ Esophageal NG Stent System. Boston Scientific) was deployed (Figure 1). Feeding was started the following day and gradually increased. Patient being followed up 3 months after surgery is asymptomatic.

\section{Discussion}

Anastomotic leaks in the thorax are traditionally feared by surgeons. Salvage surgery is largely replaced by novel therapies: stenting, injection of tissue glue and endoclipping (1). Of these, stents are the preferred option due to availability, reliability and technical simplicity. Plastic stents are preferred upon metal stents due to the removability. Gelbmann studying 9 patients after plastic stents found that $30 \%$ of them migrated, 2/9 failed to heal the fistula. Dai reported migration of stents in 5/22 and 10/22 requiring computed tomogram guided drainage after stenting (2).

Doniece using metal stents in 22 patients with leaks ranging from $1 / 4$ to complete dehiscence, had failures in $2 / 22$ and none of the stents migrated. Thirteen of these stents were later removed (3). It is impossible to perform a formal comparison between the two types of stents, as many factors are variable in each series. However, we feel that a metal stent gives sound insulation to the defect compared to plastic stents, especially when the grip is minimal at the lower gastric conduit.

In the first patient contrast study was negative while other showed a leak without clinical evidence. Thus interpretation of contrast study needs to be done with care. Management of a clinical leak is straight forward while subclinical leaks are controversial. Some prefer an initial conservative approach in subclinical leaks (4). Richardson studying 75 cases of oesophageal leaks found that delayed treatment is a major contributor for increased mortality (5). In the presence of minimally invasive endotherapy techniques, we also feel that all the leaks need aggressive management before clinical evidence of sepsis develops (5).

Linda et al compared the outcome of anastomotic leaks occurring before and after year 1986. The leak associated mortality significantly reduced from $43 \%$ to $3.3 \%$ in latter patients. They concluded that, in the presence of novel therapy previously accepted increased mortality may be no longer considered when making clinical decisions to perform a thoracic anastomosis after oesophagectomy (6).

\section{References}

1. Turkyilmaz A, Eroglu A, Aydin Y, Tekinbas C, Muharrem M, Karaoglanoglu NT. The management of esophagogastric anastomotic leak after esophagectomy for esophageal carcinoma. Diseases of the Esophagus 2009; 22(2): 119-26.

2. Gelbmann CM, Ratiu NL, Rath HC, Rogler G, Lock G, Schölmerich J, Kullmann F. Use of selfexpandable plastic stents for the treatment of esophageal perforations and symptomatic anastomotic leaks. Endoscopy 2004; 36(8): 695-9.

3. Doniec JM, Schniewind B, Kahlke V, Kremer B, Grimm $\mathrm{H}$. Therapy of anastomotic leaks by means of covered self-expanding metallic stents after esophagogastrectomy. Endoscopy 2003; 35(8): 652-8.

4. SauvanetA, Baltar J, Le Mee J, Belghiti J. Diagnosis and conservative management of intrathoracic leakage after oesophagectomy. British Journal of Surgery 1998; 85(10): 1446-9.

5. Richardson JD, Martin LF, Borzotta AP. Unifying concepts in treatment of esophageal leaks. American Journal of Surgery 1985 Jan; 149(1): 157-62.

6. Linda WM, Swisher SG, Hofstetter W, Correa AM, Mehran RJ, Rice DC, Vaporciyan AA, Walsh GL, Roth JA. Intrathoracic leaks following esophagectomy are no longer associated with increased mortality. Annals of Surgery 2005; 242(3): 392-402. 